\title{
A Primer on the Consumer Price Index
}

\author{
DENIS S. KARNOSKY
}

H

ARDLY a day goes by without mention of the effects of inflation on the economic well-being of the average citizen, as a worker and as a consumer. Most references to inflation, in turn, are in terms of the consumer price index (CPI) and the way many prices, prominently led by food and petroleum products, have shot up in the last year and a half. The CPI is often cited by the media as a measure of changes in the cost of living. It is incorporated as an escalator in labor contracts covering over 5 million workers and is now used to adjust Social Security benefits for almost 29 million people. There is increasing talk of indexing all contracts to some measure of general prices, and the consumer price index presumably would play a role.

Given its wide use, and even misuse, it is important to understand the construction of the index and some of its major shortcomings. The stated intent of the builders of the index at the Bureau of Labor Statistics (BLS) is quite limited. The CPI is designed to meas ure changes in the average price of a representative sample of goods and services purchased by typical wage earners and clerical workers in urban areas in the United States. It is interpreted much more broadly, however.

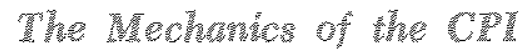

In the jargon of economists, the consumer price index is a modified Laspeyres index. What this simply means is that the CPI measures changes in the total dollar cost of a specific combination of goods and services. ${ }^{1}$ For example, if a person kept track, month to month, of the total dollar cost of buying a dozen Grade-A large white eggs, a one-pound loaf of white bread, and a 16-ounce box of comflakes, the numbers

${ }_{1} \mathrm{~A}$ Laspeyres index is a fixed-weight index, where the weights are the relative quantities as of some base period. The formula for such an index is:

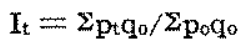

where $I_{t}$ is the value of the index in the current period, $p$ are the various component prices in the current period, po are the component prices in the base period, and $q_{0}$ are the component quantities in the base period.

The formula actually used by the BLS is somewhat different, but algebraically equivalent. The index is constructed by a chain eomputational procedure, which can be written in simplified form as:

$$
\mathrm{CPL}_{\mathrm{t}}=\Sigma_{\mathrm{pog}_{\circ}}\left(\frac{\mathrm{p}_{\mathrm{t}}}{\mathrm{p}_{\mathrm{o}}}\right) / \Sigma_{\mathrm{p}_{o} \mathrm{q}_{\circ}}
$$

would provide the basis for constructing a little index of food prices, much like the CPI. All that is left to do is divide the total cost in each month by the cost in the first month, to get a measure of the relative change in the cost. This is essentially the method used to construct an index like the CPI. The quantities of the goods and services are held constant, and the index measures the effect on total dollar cost of changes in prices of the components.

The first problem in constructing any price index is to determine the items to be priced and just how much of each to include in the bundle of goods. In the example above, the index might be interpreted as measuring the month-to-month changes in the total cost of breakfast foods. Should we also include sugar, fruit juice, coffee, or milk? Should we include bacon, or should it be sausage, and, if so, in what quantities? An index derived from a bundle containing three dozen eggs would be different from one containing only one dozen. Yet another series would result if oatmeal were substituted for cornflakes. One guide to the appropriate relative proportions, or weights, would be the actual amounts which comprise a "typical" breakfast. The index would then measure changes in the average price of a particular breakfast, instead of breakfast foods in general. The problem is to determine what makes up a "typical" breakfast.

One person probably would have little trouble with this problem, but constructing an index appropriate to the spending patterns of over 200 million people is very difficalt. Consumers spend on a wide variety of items. Some items, like food, are bought regularly and immediately consumed, while others, like houses and automobiles, are bought irregularly and yield services over a long period of time. Some scheme for determining the relative quantities of each of these goods and services is required, and, if the index is to be useful as an aggregate measure of the prices of consumer goods, the relative amounts should be representative of those actually purchased in the economy. ${ }^{2}$

The method used in deriving weights for the CPI is based on periodic surveys of consumer spending pat-

\footnotetext{
2Unfortunately no perfect means of determining the weights has yet been developed. For a presentation of some of the many schemes which have been suggested, see Irving Fisher, Making of Index Numbers (New York: Honghton Miflin Company, 1922).
} 
terns. These surveys were undertaken in 1917-19, $1934-36,1950-51,1960-61$, and $1972-733^{3}$ The results of the 1972-73 survey, along with other major changes, are scheduled to be incorporated into the index in 1977.

The survey seeks to determine the proportion of consumer spending that is devoted to various kinds of goods and services. These proportions are then used to determine the relative importance of the various prices in the index. On the basis of the survey conducted in 1960-61, estimates were made that, on average, typical wage earners and clerical workers in urban areas devoted 22.4 percent of their spending to food, 33.2 percent for housing, 10.6 percent for apparel and upkeep, 13.9 percent for transportation, 5.7 percent for medical care, 2.8 percent for personal care, and 5.1 percent for other goods and services. ${ }^{4}$ These are the weights that these various prices receive in the computation of the current consumer price index. The weights were introduced in January 1964 and have been held constant since.

Prices of over 400 separate items are currently used to construct the CPI. The list of items whose prices are sampled ranges from diapers through funeral services and includes such things as cornflakes, roof shingles, cough syrup, basketballs, and two-year-old Chevrolets and Fords. The prices are sales prices and thus include excise and sales taxes. In addition to the prices of commodities and services, the sample includes such items as real estate taxes on owned homes, utility rates, and mortgage costs. Income taxes are not included and neither are Social Security taxes. Trained representatives collect price quotations and the BLS uses strict statistical procedures for processing the data into the CPI.

These surveys are conducted in numerous metropolitan areas. The 1960-61 survey was conducted in 66 Standard Metropolitan Statistical Areas and smaller cities. The sample included 4,343 urban families of two or more persons and 517 single workers. These single persons are not necessarily unmarried, but are classified as being financially independent. Of the areas included in the survey 56 are currently sampled for price movements. Population weights for these 56 areas are used to combine the data into a city average for the United States. This city average is reported as the CPI. Price indexes for some of the individual cities are also published. For more details on the survey procedure, see Marvin Wilkerson, "The Revised City Sample for the Consumer Price Index," Monthly Labor Review (October 1960). pp. 1078-83. Also see U.S. Department of Labor, Bureau of Labor Statistics, BLS Handbook of Methods, Buln letin 1711 (1971), pp. 59-67.

these weights were introduced in January 1964 and were adjusted for changes in prices between the date of the survey and December 1963. The weights represent an estimate of how the typical urban wage earner would allocate a spending budget in December 1963 if the same items were bought as reported in the 1960-61 strvey, but at the puices prevailing in December 1963.

\section{Some Problem and Shorteoming}

Construction of a price index as comprehensive as the CPI is a very complex, difficult, and expensive task. On the one hand are the statistical problems related to sampling and processing of data. Quotations on the prices involved in all transactions are almost impossible to record. Instead, samples are designed to yield results which have a high probability of representing price behavior. On the other hand are the conceptual difficulties, the most prominent being the handling of changes in the quality of commodities and services, and changes in people's tastes and preferences. The BLS is able to collect price quotations on automobiles, for example, but they are unable to price the services rendered by a car. It is the services of an automobile that are valued by consumers, however, not just the auto itself. ${ }^{5}$ To take another example, how much more service, in dollars and cents, does a color television set yield compared to a black and white set? Even without this difference, there is the problem of changes in quality stemming from the programming policies of television networks and station owners. A decrease in the overall pleasure derived from a television set, either as entertainment or as a source of information, increases the cost of its services just like an increase in the dollar price of the set. It is impossible for anyone, other than an individual viewer, to measure objectively changes in the quality of a given commodity. A similar problem arises when new commodities are introduced.

A related problem is that the CPI is constructed as a fixed-weight index. Essentially, the CPI attempts to measure the percentage change in the amount that consumers would have to spend to purchase goods and services in the same quantities and of the same quality that they purchased when the survey was taken. Currently, the CPI measures changes in the dollar cost of items that the average urban consumer bought in 1960-61. It says nothing at all about the

\footnotetext{
${ }^{5}$ Consider a hypothetical case based on the mandatory safety devices now bnilt into cars. To the extent that they are effective in reducing the probability of bodily injury, the services of automobiles are apparently increased. It is not clear, however, that the increase in the price of a car that these safety devices represent should be discounted as reflecting an increase in quality. Other things equal, effective safety devices will result in less injury in antomobile accidents and, presumably, lower fnsurance premiums. The price of automobiles goes up and the price of insurance goes down. The result of treating the safety devices as increasing the quality of automobiles is a decrease in the index of the price of consumer goods and services. One would conclude, incorrectly, that the mandatory safety program had decreased consumer prices. In this example, all that actually happened was that the program tended to transfer resources from one industry to another, leaving average consumer prices unchanged.
} 
relative quantities or quality of the bundle of goods that consumers actually buy today. It is in this context that the CPI is not an accurate gange of changes in the cost of living.

\section{CPI rind he Cost of thing}

The CPI attempts to measure the cost of consumer goods to the "average" urban wage eamer. Being an average, the price index is only a rough approximation of the prices paid by any one individual or family. Rising food prices, for example, get a weight of about 22 percent in the index, but this understates the effect of increases in food prices on the cost of consumer goods to low income groups who devote more than 22 percent of their spending to food. At the same time it overstates the effect on someone whose spending on food accounts for only 10 percent of their total spending,

An additional problem is that consumers do not spend their income in the same manner year after year. They do not buy the same kinds of things, or even if they do, they do not buy them in the same relative amounts. However, the CPI, as a fixed-weight index, is based on the presumption that consumer spending patterns change little over time. Thus the actual average price of consumer goods is not captured in the index.

What are the factors which determine the manner by which people allocate their income among various goods and services? The foundation of economic analysis is that people attempt to maximize their own wellbeing. That is, they behave so as to derive the most satisfaction from their limited resources. People buy things which they believe (not always correctly, since we do not have perfect information about the characteristics of all goods and services) will yield them the greatest satisfaction per dollar ${ }^{7}$ The decision is a very personal one, based on each individual's subjective valuation of things he or she likes best among the available alternatives. If resources were unlimited there would be no problem, as everyone could indulge

\footnotetext{
"This shortcoming is recognized and emphasized by the Bureau of Labor Statistics, which continuously reminds readers in its publications that the CPI camot be nised as an estimate of current spending patterns or as an indicator of changes in consumer spenting. Despite this persistent warning, however, the CPI contimues to be so applied.

${ }^{3}$ Some people interpret this lack of infomation about product charactefistics as justification for govemmental intervention to prohibit "shoddy products" in the market. While no one wants to be disapoointed in a protuct he btrys, this argument fails to distinguish between purchases made in ignorance of a products true quality and those made precisely because of "inferiot" quality, and often assoctated lower price.
}

himself to the limit of his ability to absorb the services being rendered. Resources are limited, however, and the most binding constraint on an individual is his ability to command goods and services - that is, his purchasing power.

Within the context of a given level of income and ability to borrow, a person must decide where his dollars will probably yield the most satisfaction. The factors which determine this choice are each individual's subjective valuation of various items, his income, and the price of each item relative to prices of other goods and services, as well as some expectations about future income and prices. Changes in individual tastes, income, relative prices, and expectations would alter the way that income is allocated among various commodities. $^{8}$

We can get some feel for the way consumers change their spending patterns by comparing the proportion of spending devoted to the various classes of goods and services as reported in the 1960-61 survey of consumer spending to those of the 1950-51 survey. Table 1 shows the composition of spending reported in each survey since the mid-1930s." There were substantial shifts in spending patterns, highlighted by a sharp reduction in the proportion of total purchases devoted to food, and large increases in the proportion going for transportation services, medical care, and reading and recreation. This does not mean that over the decade of the $1950 \mathrm{~s}$ the average urban wage-earner decreased spending on foods and increased spending on the other items. Consumer spending for all goods and services increased 70 percent between 1950 and 1960. Spending for some items, like transportation, rose faster than spending on other items, like food. As a result the proportion spent on transportation rose and the proportion spent on food decreased.

For the entire interval from December 1952 through December 1963, the CPI was computed on the basis

\footnotetext{
SThe problem of comparing the satisfaction derived from consumption of a commodity today to the satisfaction derived yesterday is not trivial. To a style-conscious person it makes a great deal of difference whether last year's clothes are worn last year or this year. In the case of the CPI, this type of effect would be manifested, for example, in changes in the age-composition of the population. Presumably tastes change with age. For example, in 1973 , the proportion of the population under the age of 25 was estimated at 44.9 percent, up sharply from the 35.6 percent estimated in 1960 when the survey of consmer spending was taken. See Franklin Fisher and Karl Shell, Economic Theory of Price Indices (New York: Acadenic Press, 1972).

The metropolitan areas sampled changed from survey to survey. In addition, smme commodities were added and others were dropped from one survey to the next. Differences in the reported proportion reflect, in part, these changes, and not changes in consumer spending pattems.
} 


\begin{tabular}{|c|c|c|c|}
\hline Perentage & 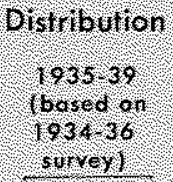 & 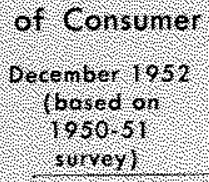 & 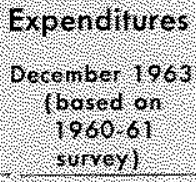 \\
\hline 1000 & $35 \% \%$ & $296 \%$ & $224 \%$ \\
\hline $1004 i n g$ & 337 & 328 & 002 \\
\hline Apporel 4 S Olloe & 110 & $8 \%$ & 10.6 \\
\hline ronsportarlot & 18,2 & 318 & 130 \\
\hline Medirol rore & $4+40$ & 31 & 57 \\
\hline 10450101801 & 12,4 & 20 & 28 \\
\hline Rerding 8 ? & 8,29 & 48 & $5 \%$ \\
\hline oher $6000 \%$, & 2,4 & & 6. \\
\hline
\end{tabular}

of weights determined in the $1950-51$ survey. ${ }^{10}$ In terms of the way people purportedly allocated their expenditures on commodities in the 1960-61 survey, changes in food prices had a smaller effect on their spending budget in late 1963 than reported in the CPI, and all other nonfood components were more important than reported in the CPI.

Changes in the price of food had an exaggerated effect on the CPI, but it is impossible to determine just when in the 1950-60 period consumer spending patterns between food and other commodities changed. The pattern of spending could have changed slowly over the period. However, the change might have come very soon after the survey was taken, for the 1950-51 period was marked by "scare-buying," as con" sumers sought to stockpile various commodities in anticipation of price controls and rationing. The Korean War had just started and the memories of the World War II experience were fresh. Alternatively, the change in spending patterns might not have come until 1960-61. when the new survey was taken. Whereas consumer spending was rising rapidly in 1950-51, the economy was in a recession during the 1960-61 period, with unemployment rising to 7 percent of the labor force. This would be expected to have an effect on the way consumers spend.

The effect of this weighting problem on the index can be seen by comparing the estimated consumption

10Prior to January 1953, the CPI was based essentially on weights deternined in the $1934-36$ period. Some interim adjustments were made during World $W_{\text {ar }}$ II and in the early Kortean Wat pertod. The 1950-51 survey served as the basis of the CPI from: January 1953 to December 1963. The $1960-61$ survey has been used since, and is not scheduled to be replaced by the results of the $1972-73$ survey until 1977 .

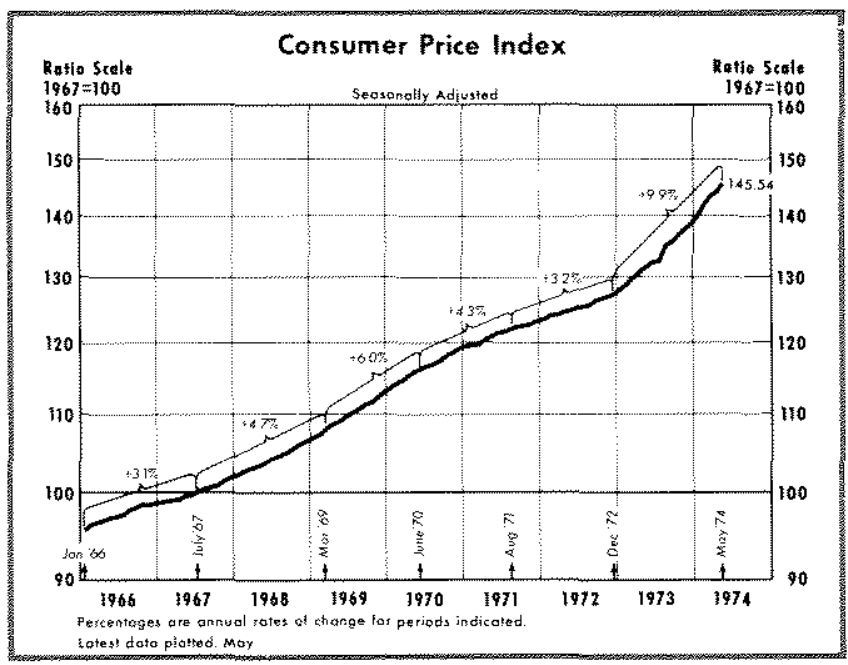

patterns in 1963 from the 1960-61 survey, with those implied by the CPI based on the $1950-51$ survey. ${ }^{11}$ If, in December of 1963, consumers would have bought goods and services in the same quantities and of the same quality as they had in 1950-51, the bundle would have cost 15.6 percent more than it did in December 1952. At December 1963 prices, food would have accounted for 28.2 percent of total spending, 30.7 percent would have gone for housing, 10.6 percent for apparel and upkeep, 11.6 percent for transportation, and 18.1 percent for health and recreation. Comparing these implied numbers to those of the 1960-61 survey reported in Table I we can see that the CPI overstated the influence of food prices on household budgets and understated the importance of all other types of consumer goods.

The problem stems from the fact that the CPI, as a fixed-weight index, camot account for changes in relative prices. A fixed-weight index presumes that the composition of their spending remains unchanged as relative prices change. When some prices rise faster than others, however, people substitute consumption of some items for others. There is no way, other than frequent surveying, to determine the extent to which

\footnotetext{
11The CPI is not a measure of the price level, but instead is a measure of changes in the level of prices from some arbitrarily selected reference point. This presents a special problem when the Bureau of Labor Statistios introduces the results of new surveys and changes the weights. They must decide a reference point from which to compute changes in prices using the new weights. The procedure they use is to link the new series to the level of the CPI of the month prior to the weight revision. There is no reason to assume that this is the appropriate price level. In fact, comparison of the 1960-61 survey data and the relative impotance in Decem. ber 1963 shows clearly that it is not. Thus while a fixedweight price index loses economic meaning when relative prices change, periodic weight revision to account for the changes in relative prices destroys the validity of the CPI as a statistical time series.
} 
people are willing or able to switch their consumption patterns when some prices change relative to others.

From 1963, when the current weights were introduced into the consumer price index, until 1973, the consumer price index increased about 45 percent. Over that same period per capita after-tax personal income in the country increased by about 96 percent. $^{12}$ The difference in these two magnitudes represents the gain in "real income" per person over the decade, as suggested by the CPI. Such an increase in real income would be expected to generate substantial shifts in the spending patterns of the average American. For example, as income increases rapidly, the demand for "necessity" items such as food would not be expected to increase as fast as the demand for some other items. "Luxury" goods, such as recreational vehicles, become increasingly attractive to families, either because of higher incomes or because of a shift in preference toward more active leisure. A fixedweight index does not account for these shifts.

\section{CPI and the Talue of the Dollar}

In the words of the BLS, "The [consumer price] index represents price change for everything people buy for living ...."13 If the statement of the BLS is interpreted literally, the CPI is intended to measure changes in the value of money. After all, prices are just exchange rates between money and other assets, including goods and services; if the CPI captures the average change of all prices, it necessarily would serve as a gauge of change in the purchasing power of money.

An index of the purchasing power of money would have to be all inclusive; that is, it would have to account for the prices of all things that can be exchanged for money. The list would include, in addition to goods and services, bonds, stocks, and investment goods. The CPI, which incorporates only prices of current consumer goods, is far short of incorporating a sufficient number of prices to be used as a measure of the purchasing power of money.

One must keep in mind that people do not only make decisions about what to consume today, but they also make plans for consumption tomorrow and years into the future. People can and do trade-off between consuming today and making provisions for consuming tomorrow. Eating a meal at a restaurant is

12This includes all persons, in addition to zrban wage earners and clinical workers.

13 Bureau of Labor Statistics, Handbook of Methods, p. 76 . current consumption. Buying a house, setting up a college fund for the children, and contributing to a retirement plan reflect plans to consume in the future. For the most part, the prices of assets which represent future purchasing power are not included in the CPI. ${ }^{14}$

What are the assets that people can buy today in order to consume tomorrow? The most obvious are durable goods, such as home appliances, automobiles, houses, and clothes. These all yield continuing service and can be bought today for consumption in the future. Many of these items are included in the CPI, but many others are not. Excluded from the index are financial assets, such as bonds, savings accounts, pension plans, and retirement funds. While they yield little direct service through ownership, they can be exchanged in the future for dollars, which in turn can be exchanged for goods and services. In considering the purchasing power of money, we must take account of the amount of future dollars that a dollar will buy today. ${ }^{1:}$ Many of these assets are not included in the CPI and, therefore, it is not a good measure of the purchasing power of money.

\section{CPI and the Carses of Inflation}

A fixed-weight index, like the CPI, is particularly susceptible to misinterpretation during short periods when the prices of some of the component parts change dramatically. ${ }^{16}$ Analysis of economy-wide developments requires a price index which measures changes in the average prices being paid in the economy. When some relatively autonomous event, like the recent oil embargo or the increase in the Russian demand for our grain, contributes to intense pressure on prices in a few markets, the CPI incorrectly trans-

14 There is no guarantee that a person will be able, in the ft1twre, to buy as much as was planned. If prices increase faster than expected, purchasing power will be less than anticipated. We know nothing about what prices will actually be in the future. We are limited, instead, to the effect today of expected future prices. Armen A. Alchian and Benjamin Klein, "On a Correct Measure of Inflation," Joumal of Money, Credit, and Banking, Part I (February 1973), pp. 173-91.

15it is popular to dellate the money stock by the CPI to get a measure of the amount of "real money balances" in the economy. On this basis, real money balances have declined over the past year. If is interesting to construct a similar series where the money stock is deflated by the market price of Aaa-rated corporate bonds. The picture is very different. This latter series admittedly is arbitrary, but is it any more so than the series using the CPI? See "Real Money Bal ances: A Misleading Indicator of Monetary Actions," this Review (February 1974), pp. 2-10.

16 Everyone who deals with data should be aware of the pitfalls. For a sobering discussion of the problems, see Oskar Morgenstern, On the Accuracy of Economic Observations (Princeton: Princeton University Press, 1963). 


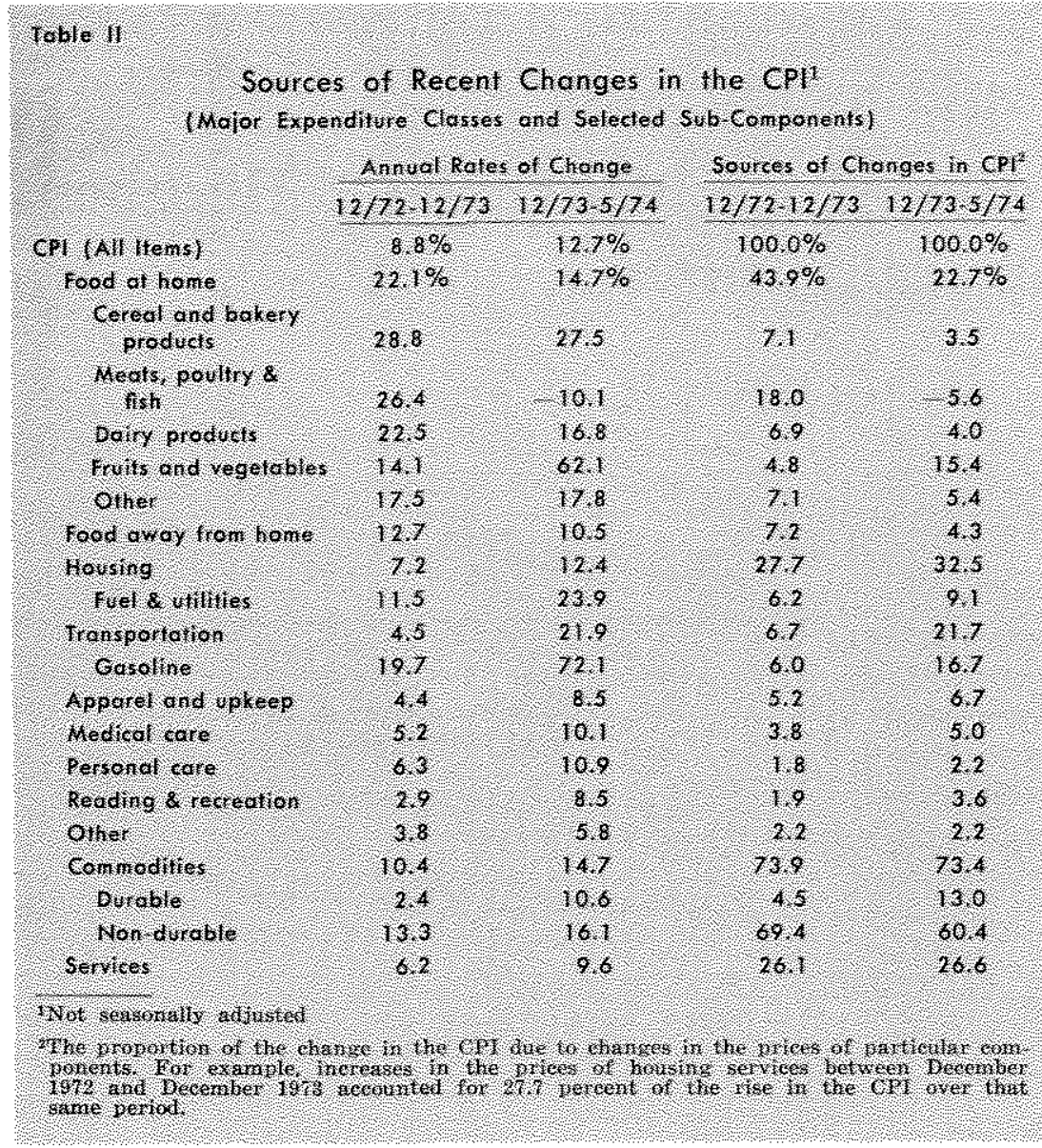

at inflation, as contributing to growth of aggregate demand. To the extent that demand was not curtailed in some other market, pressure was put on the aggregate price level. The increase in the price of food reflected the response in the market for food to this increase in aggregate demand. The rise in food prices no more caused the inflation than a crowing rooster causes the sun to rise.

If one falls into the trap of considering food prices, or oil prices, or automobile prices as causes of inflation, the logic of the position leads to the conclusion that the way to stop inflation is to decree that henceforth these individual prices shall not rise - if you do not want the sun to come up, shoot the rooster.

\section{Conclusion}

The major economic problem of the day is inflation. The only proven permanent cure for this problem is a program designed to keep the growth of aggregate demand in line with productive capacity. Some might argue that such an approach is "all right in theory, but it does not work in practice." This position, though logically absurd, is understand-

lates these individual price increases into general increases in the average price of consumer goods.

We know that the amount of food items, like beef, that consumers purchased last year decreased as the price of beef rose. The rise in the CPI reflected the increase in beef prices, but not the decrease in the amount of beef purchased. As beef prices rose, people switched to other food sources. The same phenomena occurred in the markets for gasoline and other petroleum-based fuel. Total consumption of refined petroleum products in the United States decreased by 7.4 percent from October 1973 to March 1974. This decrease in quantity was not captured in the CPI, which held the quantity constant. The rapid increases in oil prices were added in with fixed weights.

Inflation, as a persistent increase in the average level of prices, is everywhere a problem of excess aggregate demand, stemming from any of a number of sources. The huge increase in the demand for grain by the Russians, while manifested directly in the general food market, is better analyzed, for purposes of looking able, given the wide circulation of the notion that our inflation is caused by special factors, such as the oil embargo.

It is an easy matter to compute the portion of the rise in the CPI that was due to increases in food prices, or oil prices. It is also easy, but incorrect, to take one further step and say that the increases in, say, food prices accounted for 44 percent of the inflation. The prices of the components can cause the price index to rise, but that says nothing about the causes of inffation.

If shortcomings of the CPI are kept in mind, it can serve as a gauge of price pressure in a significant por tion of the economy. It does not tell us why prices are rising, just that some of them are going up. Our current inflation is little different from those of the past, except that it has been allowed to continue longer. Responsible action to keep aggregate demand in check has been and still is the only answer. 